\title{
Gene Disruption of an Arabinofuranosidase/ $\beta$-Xylosidase Precursor Decreases Sclerotinia sclerotiorum Virulence on Canola Tissue
}

\author{
William Yajima, Yue Liang, and Nat N. V. Kav \\ Department of Agricultural, Food and Nutritional Science, University of Alberta, Edmonton, Alberta, T6G 2P5, Canada
}

Submitted 15 December 2008. Accepted 12 March 2009.

\begin{abstract}
Although Sclerotinia sclerotiorum (Lib.) de Bary has been studied extensively, there are still aspects of this important phytopathogen's ability to cause disease in susceptible plants that remain unclear. A recent comprehensive proteome-level investigation of this fungus identified a number of proteins whose functions in disease initiation and progression have not been clearly established. Included among these proteins was an arabinofuranosidase $\beta$-xylosidase precursor whose role as a potential virulence factor had not been investigated previously. This article describes the generation of gene-disrupted mutant $S$. sclerotiorum unable to produce this arabinofuranosidase/ $\beta$-xylosidase precursor as well as the comparison of the virulence of this mutant with that of wild-type mycelia on susceptible canola leaves and stems. At all time points tested, the degree of necrosis was observed to be significantly greater on the plant tissue inoculated with wild-type mycelia. To our knowledge, this is the first report that clearly demonstrates that this arabinofuranosidase/ $\beta$-xylosidase precursor is a virulence factor for $S$. sclerotiorum.
\end{abstract}

Sclerotinia sclerotiorum (Lib.) de Bary is a necrotrophic phytopathogenic fungus capable of causing significant damage to over 400 different plant hosts, including numerous agriculturally important crops (Boland and Hall 1994). During carpogenic germination, ascospores are released from the apothecia that germinate from sclerotia, which are durable, melanized overwintering structures (Bolton et al. 2006). The germination of ascospores to ultimately produce mycelia capable of penetration and infection of plant hosts is usually dependent on the presence of a nutrient source such as dead or senescent flower petals (Hegedus and Rimmer 2005; Lumsden 1979). In addition to the established importance of oxalic acid production (Godoy et al. 1990), S. sclerotiorum also secretes a number of cell-wall-degrading enzymes during the infection of a susceptible host (Li et al. 2004a; Lumsden 1969; Poussereau et al. 2001a and b; Riou et al. 1991). Included among these enzymes are a number of polygalacturonases, pectinases, proteases, cellulases, and glucoamylases (Lumsden 1969, 1976; Martel et al. 2002; Poussereau et al. 2001a and b; Riou et al. 1991, 1992a and b; Waksman et al. 1991). These enzymes are responsible for weakening the plant cell wall, which consists of lignin,

Corresponding author: N. N. V. Kav; Telephone: +1 780-492-7584; Fax: +1 780-492-4265; E-mail: nat@ualberta.ca

* The $\boldsymbol{e}$-Xtra logo stands for "electronic extra" and indicates that Figure 2 appears in color online. protein, wax, polysaccharide matrix, and microfibrils made of cellulose (Cassab 1998; Cosgrove 2005). The polysaccharide matrix of a primary cell wall is made mainly of hemicelluloses (arabinoxylan, mannan, and xyloglucan) and pectin (Cosgrove 2005). Pectin within the primary cell wall consists mainly of homogalacturonan, arabinan, xylogalacturonan, and rhamnogalacturonan I and II (Cosgrove 2005). Arabinofuranose residues can be commonly found in plant cell walls as part of arabinofuranose-containing hemicelluloses such as arabinoxylans (Miyanaga et al. 2006). The polysaccharide, xylan, which is made up of the carbohydrate xylose, may also be present within the plant cell walls in the form of hemicellulose (Polizeli et al. 2005; Weinstein and Albersheim 1979).

Because of its ability to cause significant losses in economically important crops, S. sclerotiorum has been the focus of many research programs and scientists have successfully annotated its genome, investigated the fungus at the level of gene expression ( $\mathrm{Li}$ et al. 2004b; Sexton et al. 2006), and performed proteome-level studies (Yajima and Kav 2006). These transcriptand proteome-level studies have identified a number of genes and proteins that are believed to be intimately involved in virulence and pathogenicity. However, these studies have also led to the identification of numerous genes and proteins whose precise activities in the lifecycle of $S$. sclerotiorum have not been completely elucidated. Among the secreted proteins identified in a proteome-level analysis of S. sclerotiorum (Yajima and Kav 2006) whose role as a potential virulence factor had not been previously determined in this phytopathogen was an arabinofuranosidase. Since the publication of the proteome-level investigation of $S$. sclerotiorum, the nomenclature for the identified enzyme has changed slightly and it is now referred to as an arabinofuranosidase $/ \beta$-xylosidase precursor. The gene encoding this 487-amino-acid enzyme is located on supercontig 3 (locus: SS1G_02462.1) according to the S. sclerotiorum genome database of the Broad Institute (Cambridge, MA, U.S.A.). The encoded enzyme will be hereafter referred to in this article as Ssaxp. There have been reports of the existence of other bifunctional enzymes in bacteria as well as in fungi exhibiting both arabinofuranosidase and xylosidase activity (Margolles-Clark et al. 1996; Utt et al. 1991). These arabinofuranosidase and $\beta$-xylosidase enzymes are responsible for catalyzing the hydrolysis of glycosidic bonds, which are found in the plant cell walls linking saccharide units to each other (Herron et al. 2000; Jordan and $\mathrm{Li} \mathrm{2007).} \mathrm{Although} \mathrm{arabinofuranosidases} \mathrm{and} \beta$-xylosidases are enzymes with dual roles, some of these enzymes have either the arabinosidase or xylosidase activity as the predominant function (Jordan and Li 2007). Therefore, Ssaxp likely contributes to the degradation of plant cell walls, thereby possibly allowing easier penetration and invasion of susceptible plants. 
In this article, we describe the generation of Ssaxp-disrupted mutant $S$. sclerotiorum and discuss the effect of this gene disruption on the virulence of the fungus on canola leaves and stems.

\section{RESULTS}

Generation of gene-disrupted mutant $S$. sclerotiorum.

Following confirmation that the hygromycin phosphotransferase $(h p h)$ gene was correctly inserted into the amplified Ssaxp fragment, the prepared $S$. sclerotiorum protoplasts were transformed with the linearized hph-Ssaxp DNA fragment for
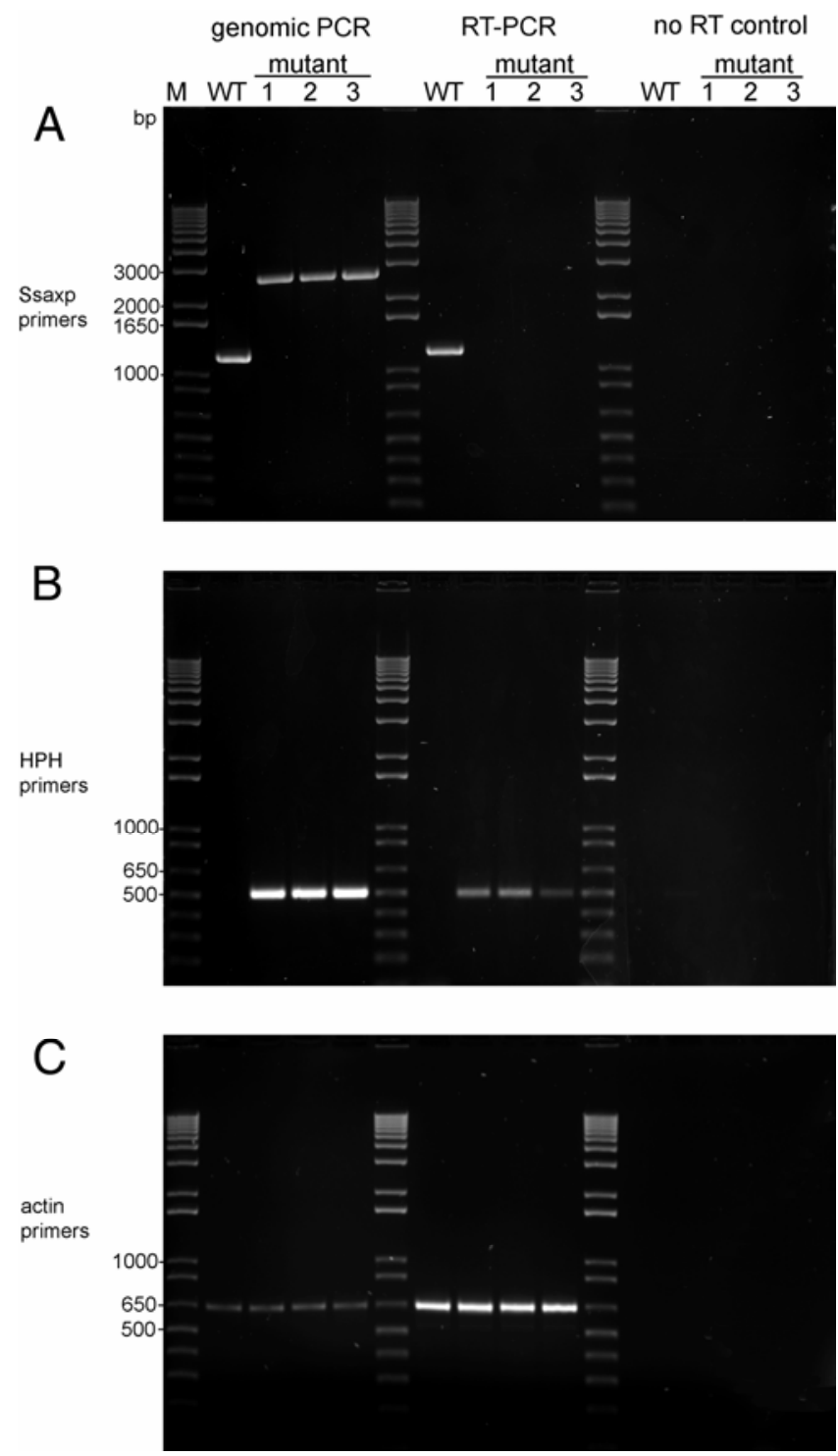

Fig. 1. Gel images of polymerase chain reaction (PCR) amplification products. A, When Ssaxp-specific primers were used, only the wild-type (WT) Sclerotinia sclerotiorum produced the expected sized $(1.2 \mathrm{~kb})$ gene fragment and transcript. The $2.6-\mathrm{kb}$ genomic PCR amplification product present in the lanes for the mutant mycelia was the result of the insertion of the hygromycin phosphotransferase $(h p h)$ gene $(1.4 \mathrm{~kb})$ into Ssaxp. The lack of observable amplification product from the reverse-transcription (RT)-PCR using $S$ saxp-specific primers and mutant mycelia indicated the absence of the Ssaxp transcript. B, When the $h p h$-specific primers were used, only the mutant mycelia produced the $h p h$ gene fragment and transcript. C, The genomic PCR and RT-PCR for actin, which served as the internal control, produced an amplification product of the expected size. The lack of observable amplification product in the no-RT controls indicated that the amplification products produced in the RT-PCR were not the result of DNA contamination (A through C). The size marker used was a 1-kb Plus DNA size marker (M). homologous recombination and subsequent insertion of $\mathrm{hph}$ into the fungal genome. Regenerating colonies could be seen under a dissecting microscope approximately 3 days after plating the transformed protoplasts and, on the fifth day after plating, five regenerating colonies, which appeared as mycelial growth that had emerged through the top agar, were excised from the selection plates and transferred to potato-dextrose agar (PDA) media containing hygromycin. Another five colonies were excised from the plates and transferred onto fresh PDA-hygromycin media over the next 3 days. A control transformation was performed in which no linearized $h p h-S s a x p$ was added to the protoplasts in order to confirm that the concentration of hygromycin in the regenerating media (RM) top agar was appropriate. No regenerating colonies were observed emerging through the RM top agar on this control plate, even after 10 days.

The results of the genomic polymerase chain reaction (PCR) and reverse-transcription (RT)-PCR of selected colonies are shown in Figure 1. When genomic PCR was performed using Ssaxp-specific primers flanking the insertion site for $h p h$, a single amplification product whose size was approximately 2.6 $\mathrm{kb}$ was observed for the transformants; however, when the same primers were used for wild-type $S$. sclerotiorum, the resulting amplification product was approximately $1.2 \mathrm{~kb}$ (Fig. 1A). This size difference corresponded with the expected size of the inserted $h p h$. Genomic PCR was performed using $h p h$ specific primers to confirm the presence of $h p h$ in the transformants, and the resulting gel image (Fig. 1B) clearly shows amplified product only for the transformants and not for the wildtype mycelia. The $h p h$-specific primers were designed to amplify a $0.5-\mathrm{kb}$ fragment of the whole $h p h$. In order to determine if Ssaxp and $h p h$ were being expressed, RT-PCR was performed to reveal that the Ssaxp transcript was present only in the wild-type mycelia (Fig. 1A) whereas the $h p h$ transcript was present only in the transformants (Fig. 1B). The amplification of the actin internal control (Fig. 1C) provided evidence that the lack of amplification of the Ssaxp and hph transcripts observed for the mutant fungi and wild-type fungus, respectively, was not the result of poor cDNA quality or insufficient cDNA. Furthermore, the lack of any observable amplification products for the PCR using RNA as the template (i.e., no reverse transcription or no-RT control) indicated that the amplification products resulting from the RT-PCR were not the result of the presence of contaminating DNA (Fig. 1A through C).

It should be noted that, of the 10 regenerating colonies that were excised from the selection plates, 6 produced an amplification product $2.6 \mathrm{~kb}$ in size during genomic PCR with Ssaxpspecific primers while the others produced a smaller amplification product or did not produce any amplification product (data not shown). These four regenerating colonies were thought to be false positives and were not used in subsequent experiments. Only the six transformants that produced a $2.6-\mathrm{kb}$ genomic PCR amplification product were used and, although Figure 1 shows the genomic PCR and RT-PCR results for only mutants no. 1 to 3 , all six transformants produced identical results (data not shown). The results for the subsequent Brassica napus leaf and stem inoculations are presented and discussed only for mutants no. 1 to 3 even though all six showed consistent results (data not shown).

\section{Differences in virulence} of gene-disrupted $S$. sclerotiorum mutants.

The appearance of representative leaves and stems inoculated with wild-type or mutant mycelia is shown in Figure 2. The results of the detached canola leaf and stem inoculations are shown in Figures 3 and 4, respectively. Disease symptoms, as indicated by the expanding necrotic lesion surrounding the 
agar plug, were observed on all inoculated leaf and stem tissue. However, the necrotic lesion was significantly smaller on the plant tissue inoculated with the mutant mycelia at all time points (Figs. 2 through 4). Furthermore, the amount of mycelial growth appeared to be greater on the canola tissue inoculated with wild-type $S$. sclerotiorum because the white, cotton-like mycelia characteristic of $S$. sclerotiorum infection (Bolton et al. 2006) was observed on leaves at $48 \mathrm{~h}$ postinoculation (hpi) whereas it did not appear on canola leaves inoculated with the mutant mycelia even at 72 hpi (Fig. 2A). Similarly, the white, cotton-like mycelia appeared first on canola stems inoculated with wild-type mycelia at 72 hpi whereas it was not apparent on the stems inoculated with mutant mycelia until 96 hpi (Fig. 2B). Although disease symptoms were observed on all leaf and stem tissue tested, the necrotic lesions appeared within the first $24 \mathrm{hpi}$ on leaves but required approximately $48 \mathrm{~h}$ before noticeable symptoms were observed on inoculated stems. At 48 and $72 \mathrm{hpi}$, there was no significant difference in the area of necrosis on the leaves inoculated with $S$. sclerotiorum mutants, even though the necrotic lesion caused by mutant no. 3 appeared
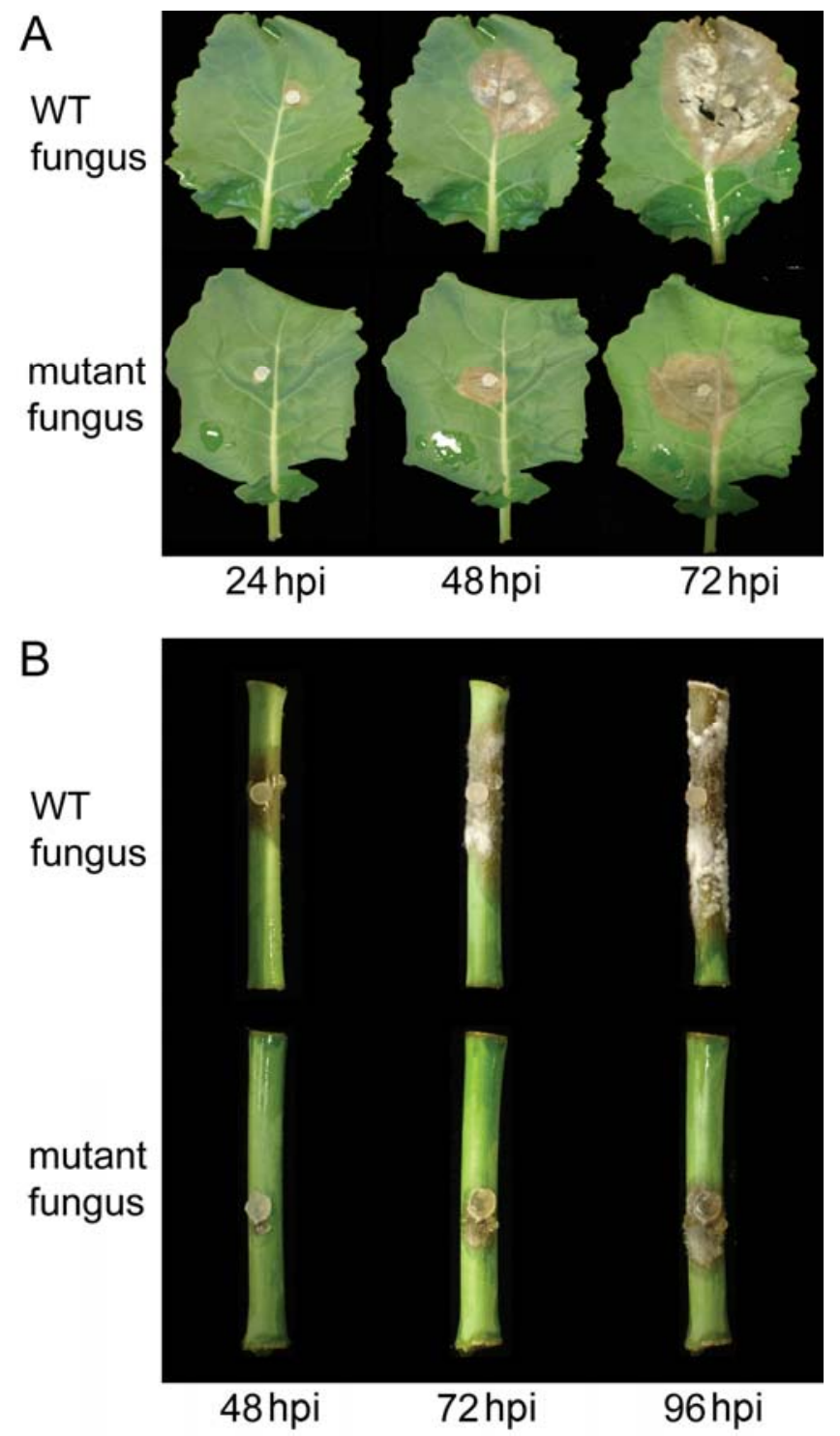

Fig. 2. Appearance of the canola leaves and stems inoculated with either wild-type (WT) Sclerotinia sclerotiorum or gene-disrupted mutants. The representative images show that the WT mycelia caused significantly more disease symptoms than the mutant mycelia on both $\mathbf{A}$, leaves and $\mathbf{B}$, stems at all time points. to be larger than the necrotic area on the leaves inoculated with mutants 1 and 2 (Fig. 3B and C).

\section{DISCUSSION}

One of the most important barriers that phytopathogens must overcome in order to effectively infect plants is the plant

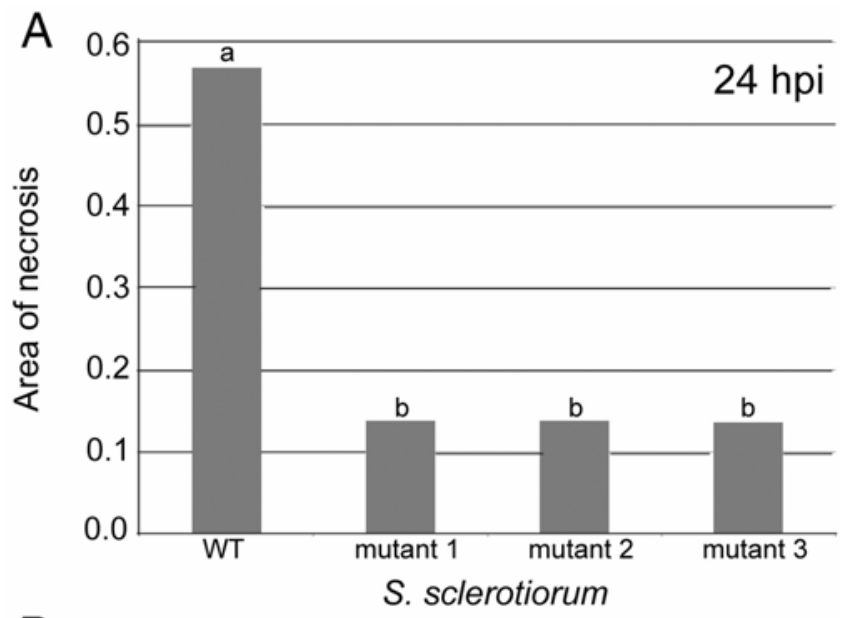

B

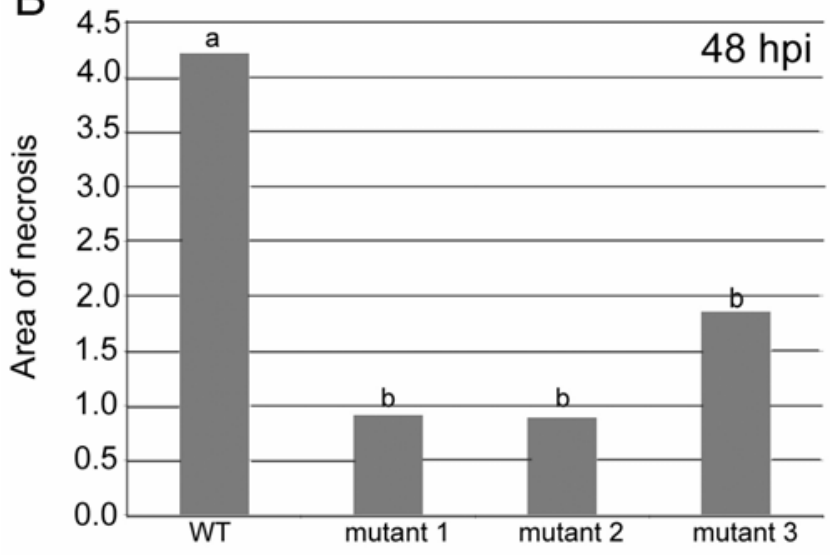

C

S. sclerotiorum

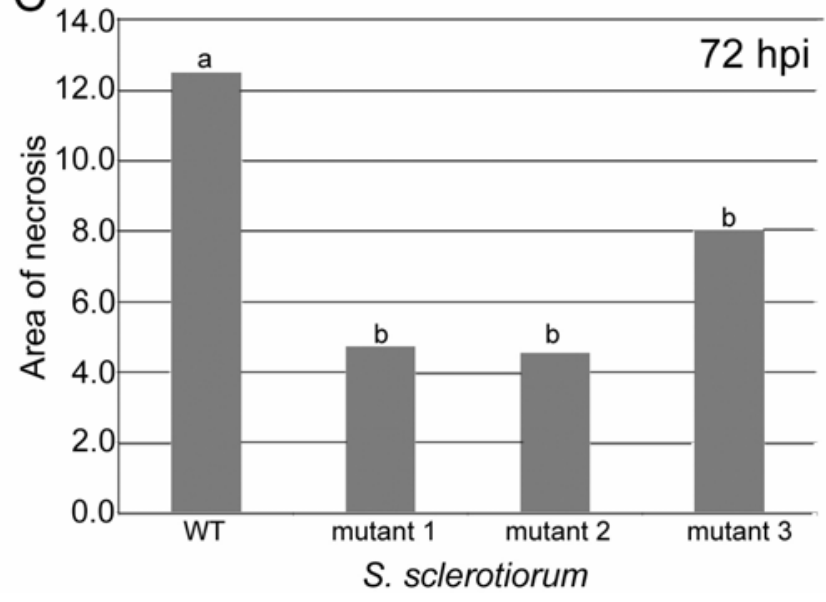

Fig. 3. Comparison of the area of necrosis on inoculated canola leaves. The degree of necrosis was significantly greater on leaves inoculated with wildtype (WT) Sclerotinia sclerotiorum compared with the gene-disrupted mutants A, 24; B, 48; and C, $72 \mathrm{~h}$ postinoculation (hpi. The area of necrosis was based on the number of highlighted pixels corresponding to the necrotic lesion, which was then normalized against the area of a square $\left(1 \mathrm{~cm}^{2}\right)$. Significant differences according to analysis of variance analysis by SAS $(P<$ 0.05 ) are indicated by the different letters above the columns. 
cell wall, which consists mainly of polysaccharides (Herron et al. 2000). It is for this reason that phytopathogens secrete enzymes such as glycoside hydrolases and polysaccharide lyases capable of breaking down the polysaccharide matrix found within the cell wall (Herron et al. 2000). The pectin found in the cell walls of plants contains regions where the polysaccharides are highly branched and methyl esterified as well as regions in which the polysaccharides are unbranched and nonmethyl-esterified (Jarvis 1984). The degradation of pectin by the various pectinases secreted by $S$. sclerotiorum can provide the fungus with a weakened plant cell wall which can serve as
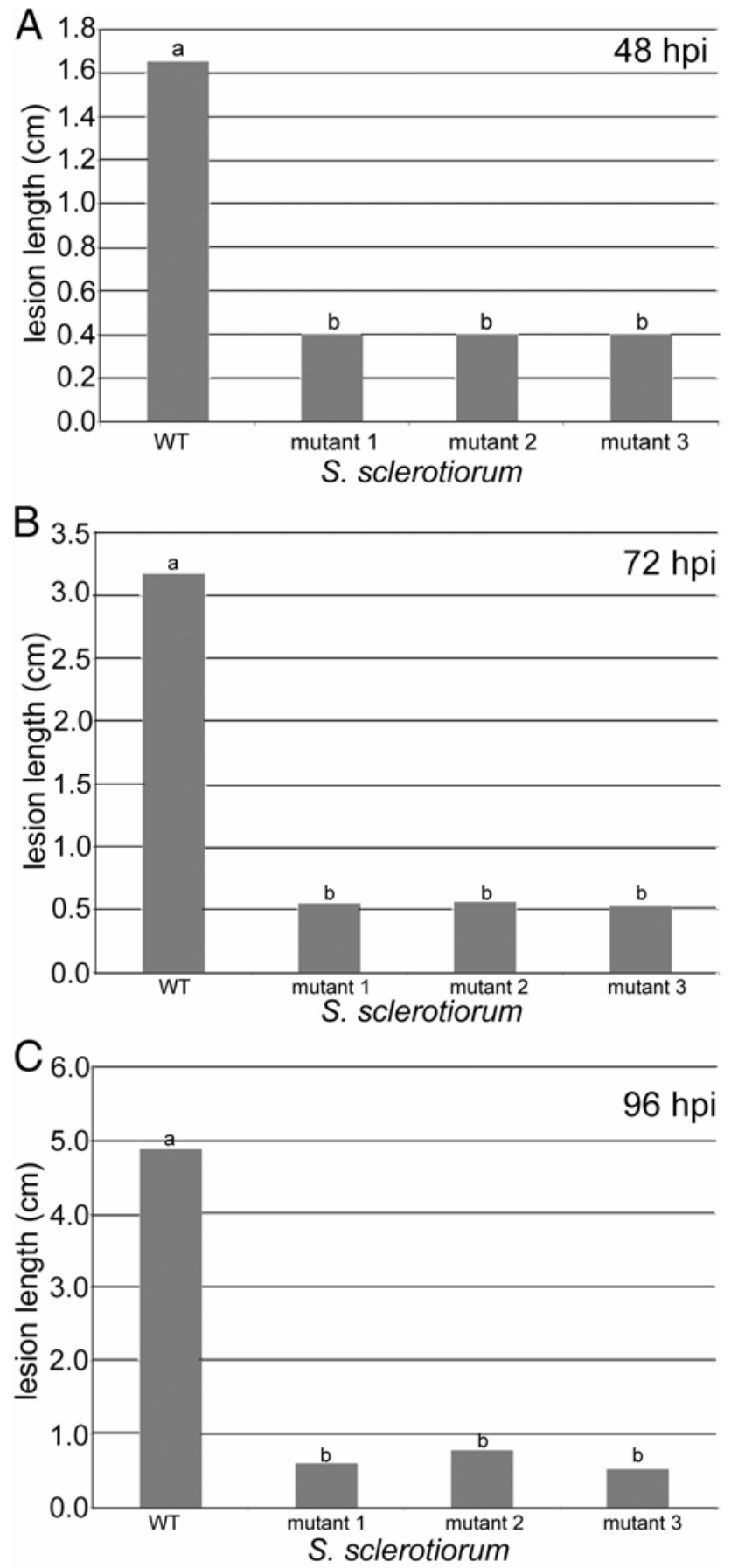

Fig. 4. Comparison of the length of necrotic lesions on inoculated canola stems. Lesion length was significantly greater on stems inoculated with wild-type (WT) Sclerotinia sclerotiorum compared with the gene-disrupted mutants $\mathbf{A}, 48 ; \mathbf{B}, 72$; and $\mathbf{C}, 96$ h postinoculation (hpi). Significant differences according to analysis of variance analysis by SAS $(P<0.05)$ are indicated by the different letters above the columns. an entry point for the invading pathogen (Alghisi and Favaron 1995; Bolton et al. 2006). The focus of this study was Ssaxp and its importance to the virulence of S. sclerotiorum.

In an effort to generate Ssaxp-disrupted mutants to determine whether eliminating this particular gene product causes any changes to virulence, $S$. sclerotiorum protoplasts were transformed with $h p h$-Ssaxp to introduce $h p h$ into the genome within Ssaxp. It is likely that the mutants were still virulent, albeit less so than the wild-type mycelia, because of the presence of the numerous aforementioned plant cell-wall-degrading enzymes that would enable the mycelia to infect the susceptible canola plant tissue even in the absence of Ssaxp. Because of these other cell-wall-degrading enzymes, some of which may have redundant activities, it might seem somewhat unexpected that eliminating the expression of a single gene encoding a hydrolytic enzyme could result in decreased virulence. However, it has been demonstrated that the disruption of a single pectin methylesterase gene can lead to reduced virulence in Botrytis cinerea (Vallette-Collet et al. 2003). It has been suggested that a number of the hydrolytic enzymes secreted by phytopathogens are essential for ensuring full virulence (Vorwerk et al. 2004). Furthermore, although it is believed that some products of cell wall degradation can stimulate plant host defense responses (Bruce and West 1982), it has also been observed that some products of cell wall degradation, such as galacturonic acid, can induce the production of other cell-walldegrading enzymes in S. sclerotiorum (Fraissinet-Tachet and Fevre 1996; Hegedus and Rimmer 2005). The lack of Ssaxp in the mutant would have decreased the cell-wall-degrading arsenal by one bifunctional enzyme, thereby presumably reducing the amount of cell-wall-degradation products generated during infection. Therefore, it is possible that the smaller necrotic lesions observed on the plant material inoculated with the mutant was not only due to the absence of Ssaxp but may have also been because of the reduced induction of other enzymes known to be involved in pathogen invasion. A comparison of gene expression levels of known cell-wall-degrading enzymes between the wild-type and mutant fungus grown in appropriate media may be a viable method to test this hypothesis and will be explored in our laboratory.

The identification of Ssaxp as a virulence factor provides valuable information regarding the infection process for $S$. sclerotiorum and this information may prove beneficial for the agriculture industry. First, the viability of using antibodies specific for fungal phytopathogens to protect crops from disease has been explored (Peschen et al. 2004) and there may be merit to exploring the possibility of developing an effective antibody-based disease management tool targeting the identified virulence factor to inhibit the ability of S. sclerotiorum to infect susceptible crops. Second, Ssaxp is similar to proteins found in other fungi, including those that may have agricultural significance, such as Botryotinia fuckeliana (83\% identity based on amino acid sequence), Pyrenophora tritici-repentis (71\% identity), Phaeosphaeria nodorum (71\% identity), Fusarium oxysporum (70\% identity), and Gibberella zeae (68\% identity), among others. Therefore, it is possible that the information described in this article regarding the apparent importance of this gene for full virulence may have relevance to other important phytopathogens capable of causing significant yield losses in agricultural crops.

The work described in this article was initiated based on the results of a proteome-level investigation of S. sclerotiorum. The subsequent identification of Ssaxp as a virulence factor for this fungus clearly demonstrates the considerable value of performing proteomics-based studies of plant pathogens. Furthermore, merely compiling a list of proteins present in a particular pathogen does not take full advantage of the information 
generated in comprehensive proteomics-based investigations. Determining the roles, if any, for the identified proteins whose importance to plant-pathogen interaction has not been studied and is, therefore, currently unknown may provide new insights into the virulence of a phytopathogen. Included among these proteins are hypothetical or putative proteins that may be identified in global proteomics-based studies. Ascribing functions to these proteins is likely to lead to a more thorough understanding of the life cycle or infection process of a particular phytopathogen, which may ultimately lead to the development of novel disease management strategies.

\section{MATERIALS AND METHODS}

\section{Fungal growth conditions.}

The $S$. sclerotiorum stock used in the following experiments was kindly provided by S. Strelkov (University of Alberta). It was isolated from infected canola and was maintained as a glycerol stock in liquid nitrogen until used. The stock S. sclerotiorum was maintained on PDA (Becton Dickinson, Franklin Lakes, NJ, U.S.A.) media and subculturing of the fungus was performed by slicing mature sclerotia in half using a sterile scalpel blade and inoculating fresh PDA with the sliced sclerotia. The gene-disrupted $S$. sclerotiorum mutants were maintained on PDA supplemented with hygromycin $(100 \mu \mathrm{g} / \mathrm{ml})$.

\section{S. sclerotiorum genomic DNA extraction.}

Total genomic DNA was extracted using a modified version of the method described by Yelton and associates (1984) and Rollins (2003). Five PDA plugs $(0.4 \mathrm{~cm}$ in diameter) containing actively growing $S$. sclerotiorum mycelia were used to inoculate $100 \mathrm{ml}$ of pectin media $(1 \%$ [wt/vol] pectin [Acros Organics,

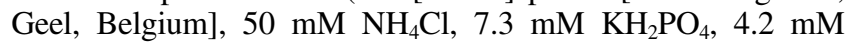
$\mathrm{MgSO}_{4}, 6.7 \mathrm{mM} \mathrm{KCl}$, and $0.07 \mathrm{mM} \mathrm{FeSO}_{4}$ ) in a 250 -ml Erlenmeyer flask, which was incubated at room temperature with agitation on a platform shaker $(100 \mathrm{rpm})$ for 5 days. The mycelia were harvested by filtration through filter paper and washed by centrifugation three times with sterile water $(10,000 \times g, 10 \mathrm{~min}$, $4^{\circ} \mathrm{C}$ ). The mycelia were flash frozen in liquid nitrogen and lyophilized overnight. Lyophilized mycelia $(30 \mathrm{mg})$ were added to a sterile $1.5-\mathrm{ml}$ plastic tube and then ground to a fine powder using a metal spatula. Buffer $1(500 \mu \mathrm{l})(50 \mathrm{mM}$ EDTA, $0.2 \%$ [wt/vol] sodium dodecyl sulfate, $\mathrm{pH} 8.5$ ) was added to the ground mycelia and the solution was vortexed briefly. The solution was incubated in a water bath set at $68^{\circ} \mathrm{C}$ for $10 \mathrm{~min}$, vortexed briefly, and centrifuged $\left(21,000 \times g, 5 \mathrm{~min}, 22^{\circ} \mathrm{C}\right)$. The supernatant was transferred to a new sterile $1.5-\mathrm{ml}$ plastic tube containing $30 \mu \mathrm{l}$ of $8 \mathrm{M}$ potassium acetate, $\mathrm{pH} 10.0$, and the solution was incubated on ice for $5 \mathrm{~min}$. The solution was centrifuged $\left(21,000 \times g, 5 \mathrm{~min}, 4^{\circ} \mathrm{C}\right)$, transferred to a new, sterile, $1.5-\mathrm{ml}$ plastic tube, and the centrifugation was repeated. The supernatant was carefully transferred to a new, sterile, $1.5-\mathrm{ml}$ plastic tube so as not to disturb the pellet and $600 \mu \mathrm{l}$ of isopropanol was added. The solution was mixed vigorously and centrifuged $\left(21,000 \times g, 5 \mathrm{~min}, 4^{\circ} \mathrm{C}\right)$. After removing the supernatant, the DNA pellet was inverted to dry and the DNA was resuspended in $200 \mu \mathrm{l}$ of Tris-EDTA buffer $(10 \mathrm{mM}$ Tris, $1 \mathrm{mM}$ EDTA, pH 8) containing RNase A (20 $\mu \mathrm{g} / \mathrm{ml})$ (Ambion, Austin, TX, U.S.A.). The solution was incubated in a water bath set at $37^{\circ} \mathrm{C}$ for $30 \mathrm{~min}$. Then, $10 \mu \mathrm{l}$ of $10 \mathrm{M}$ lithium chloride and 500 $\mu \mathrm{l}$ of $95 \%$ ( $\mathrm{vol} / \mathrm{vol})$ ethanol were added and the solution was vortexed and then centrifuged $\left(21,000 \times g, 5 \mathrm{~min}, 22^{\circ} \mathrm{C}\right)$. The supernatant was removed and the pelleted DNA was dried. The DNA was resuspended in $30 \mu \mathrm{l}$ of sterile water and then analyzed by agarose gel electrophoresis, and nucleic acid concentration was determined using a NanoDrop 1000 (Thermo Scientific, Wilmington, DE, U.S.A.).

\section{Construction of Ssaxp disruption vector.}

In order to confirm that the correct gene was targeted for disruption, the peptide sequence (AYGVFISPGTGYR) that was provided in the proteome-level investigation of $S$. sclerotiorum for the identified arabinofuranosidase protein was used to perform a BLAST search to determine which specific gene to target (Yajima and Kav 2006). Upon verifying that the peptide sequence was present in S. sclerotiorum only in Ssaxp, primers were designed to PCR amplify a 2,216-bp fragment from $918 \mathrm{bp}$ upstream of the start codon to $1,295 \mathrm{bp}$ downstream of the start codon. A BLAST search was performed to verify that the primers could only amplify the specific target sequence. The amplified fragment consisted of 1,298 bp of the $1,767 \mathrm{bp}$ coding sequence and included the one intron present in this gene. The sequence of the arabino forward primer was 5'-GGTGGTGGGTACCATGGAGAAGAATATTAGCTTGAA G- $3^{\prime}$ and the sequence of the arabino reverse primer was $5^{\prime}$-AT ATTATCTCGAGAGACCAGGTCCGCTGGTCAATGATG-3'. Each of the primers encoded a specific restriction enzyme sequence (KpnI for the forward primer and XhoI for the reverse primer) to enable insertion of the amplified DNA fragment into selected vectors. PCR was performed using the Expand high fidelity PCR system (Roche, Laval, Canada) with a program consisting of $95^{\circ} \mathrm{C}$ for $5 \mathrm{~min}$ followed by 30 cycles of $95^{\circ} \mathrm{C}$ for $1 \mathrm{~min}, 60^{\circ} \mathrm{C}$ for $1 \mathrm{~min}$, and $72^{\circ} \mathrm{C}$ for $2.5 \mathrm{~min}$. PCR was completed with a 7 -min incubation at $72^{\circ} \mathrm{C}$ followed by a hold at $4{ }^{\circ} \mathrm{C}$. The PCR products were analyzed in a $1 \%(\mathrm{wt} / \mathrm{vol})$ agarose gel and the DNA bands were purified using the QIAquick gel extraction kit (Qiagen, Mississauga, Canada) for subsequent digestion with $K p n I$ and $X h o I$ for $2 \mathrm{~h}$ at $37^{\circ} \mathrm{C}$ (New England Biolabs, Pickering, Canada). The digested products were gel purified using the QIAquick Gel Extraction kit and were inserted into a KpnI- and XhoI-digested pET30a vector (Novagen, Mississauga, Canada). The ligation reaction was performed using the Rapid DNA ligation kit (Roche) according to the manufacturer's recommended procedure. The ligation mix $(10 \mu \mathrm{l})$ was used to transform competent DH5 $\alpha$ Escherichia coli cells $(50 \mu \mathrm{l})$ (Invitrogen, Burlington, Canada), which were plated on Luria-Bertani agar plates containing kanamycin (50 $\mu \mathrm{g} / \mathrm{ml}$ ) and incubated at $37^{\circ} \mathrm{C}$ overnight. Colony PCR using randomly selected bacterial colonies was performed using the same PCR program as described earlier to select those clones containing the desired Ssaxp-pET30a construct. Plasmid DNA was purified from selected positive clones using the QIAprep Spin Miniprep kit (Qiagen) and was sequenced using the BigDye Terminator v3.1 cycle sequencing kit (Applied Biosystems, Foster City, CA, U.S.A.) and the ABI PRISM 3100 Genetic Analyzer (Applied Biosystems) according to the manufacturer's recommended procedures to verify that mutations were not introduced into the amplified DNA during PCR. The Ssaxp-pET30a construct was digested with the SacII restriction enzyme (New England Biolabs) and the hph-containing pCB1003 vector (Carroll et al. 1994) obtained from the Fungal Genetics Stocks Center (University of Missouri, Kansas City) was digested with SalI (New England Biolabs) for $2 \mathrm{~h}$ at $37^{\circ} \mathrm{C}$ and then gel purified with the QIAquick Gel Extraction kit. In order for successful blunt end ligation, the digested products were treated with DNA polymerase I, Large (Klenow) Fragment (New England Biolabs) for $15 \mathrm{~min}$ at $25^{\circ} \mathrm{C}$ and then were purified using the QIAquick Gel Extraction kit. Aliquots $(3 \mu \mathrm{l})$ of the DNA products were analyzed in a $1 \%(\mathrm{wt} / \mathrm{vol})$ agarose gel. The remaining aliquots were used in a blunt end ligation reaction with the Rapid DNA Ligation kit followed by transformation of competent DH5 $\alpha$ E. coli cells and colony PCR as described previously. The expected size of the amplified DNA product from the colony PCR was approximately 3,600 bp (2,216-bp Ssaxp fragment and 1,400-bp hph). Plasmids 
were purified from clones that produced DNA bands of the expected size and then sequenced as described previously to ensure correct insertion of $h p h$ into the Ssaxp fragment.

\section{Preparation of fungal protoplasts.}

The protoplasting of $S$. sclerotiorum for use in transformation was performed based on the procedure described by Kohn and associates (1991) and Rollins (2003). Five mycelia-containing PDA agar plugs $(0.4 \mathrm{~cm}$ in diameter $)$ collected from the outer margins of actively growing mycelia were used to inoculate $25 \mathrm{ml}$ of potato dextrose broth (PDB) (Becton Dickinson) in a sterile plastic petri dish, which was incubated at room temperature for 4 days without agitation. The hyphae were collected from the surface of the media, placed on four layers of sterile cheesecloth in a funnel, and washed first with sterile water and then with protoplast buffer $\left(0.8 \mathrm{M} \mathrm{MgSO}_{4} \cdot 7 \mathrm{H}_{2} \mathrm{O}\right.$, $0.2 \mathrm{M} \mathrm{C}_{6} \mathrm{H}_{5} \mathrm{Na}_{3} \mathrm{O}_{7} \cdot 2 \mathrm{H}_{2} \mathrm{O}, \mathrm{pH}$ 5.5). The washed hyphae were then chopped into smaller pieces using a sterile scalpel blade and transferred into a sterile, 125-ml Erlenmeyer flask. Lysing enzymes from Trichoderma harzianum (200 mg) (SigmaAldrich, St. Louis) were dissolved in $3 \mathrm{ml}$ of buffer (1 M sorbitol, $50 \mathrm{mM}$ sodium citrate, $\mathrm{pH}$ 5.8) and then added to $17 \mathrm{ml}$ of protoplast buffer. The solution was added to the hyphaecontaining Erlenmeyer flask, which was incubated at $28^{\circ} \mathrm{C}$ with gentle agitation $(100 \mathrm{rpm})$ on a platform shaker for $3 \mathrm{~h}$. The resulting protoplasts were filtered through sterile cheesecloth to remove any remaining hyphal fragments and were collected in a sterile, $125-\mathrm{ml}$ Erlenmeyer flask. Then, $30 \mathrm{ml}$ of 0.6 $\mathrm{M} \mathrm{KCl}$ was poured over the cheesecloth and was collected in the protoplast-containing flask. The protoplast solution was centrifuged in 50 - $\mathrm{ml}$ plastic tubes $\left(3,000 \times g, 10 \mathrm{~min}, 4^{\circ} \mathrm{C}\right)$ and the pelleted protoplasts were washed twice with $10 \mathrm{ml}$ of STC buffer (1 M sorbitol; $50 \mathrm{mM}$ Tris, $\mathrm{pH} 8 ; 50 \mathrm{mM} \mathrm{CaCl} 2$. $2 \mathrm{H}_{2} \mathrm{O}$ ). Protoplasts in STC buffer were counted using the Bright Line Hemacytometer with a $0.4-\mathrm{mm}$ cover slip (Fisher Scientific, Ottawa, Canada) and then diluted with STC buffer to a final concentration of $1 \times 10^{8}$ protoplasts $/ \mathrm{ml}$. Aliquots consisting of $1 \mathrm{ml}$ of protoplast solution, $12.5 \mu \mathrm{l}$ of dimethyl sulfoxide, $62.5 \mu \mathrm{l}$ of heparin $(5 \mathrm{mg} / \mathrm{ml}$ prepared in STC buffer), and $250 \mu \mathrm{l}$ of polyethylene glycol (PEG) solution $\{40 \%$ [wt/vol] PEG 4000; $0.6 \mathrm{M} \mathrm{KCl} ; 50 \mathrm{mM}$ Tris, $\mathrm{pH} 8 ; 50$ $\mathrm{mM} \mathrm{CaCl} 2$ ] were prepared and then stored at $-80^{\circ} \mathrm{C}$ until used.

\section{Transformation of $S$. sclerotiorum protoplasts.}

Prior to transformation, the $h p h$-Ssaxp-pET30a construct described earlier was digested with $K p n I$ and XhoI and the linearized $h p h$-Ssaxp fragment was purified with the QIAquick Gel Extraction kit. The transformation of the fungal protoplasts was performed based on the procedure described by Rollins (2003). Briefly, protoplasts $\left(1 \times 10^{7}\right)$ in $100 \mu$ of STC buffer were added to approximately $4 \mu \mathrm{g}$ of linearized $h p h$ Ssaxp fragment and then incubated on ice for $60 \mathrm{~min}$. PEG solution $(1 \mathrm{ml})$ was added to the DNA-protoplast solution, which was then mixed gently and incubated for $20 \mathrm{~min}$ at room temperature. The solution was spread evenly over the surface of RM bottom agar $(0.7 \mathrm{M}$ sucrose, $0.05 \%$ [wt/vol] yeast extract, $1.5 \%$ [wt/vol] agar) in a petri dish, which was then incubated overnight in the dark at room temperature. RM top agar $(5 \mathrm{ml})(0.7 \mathrm{M}$ sucrose, $0.05 \%$ [wt/vol] yeast extract, $0.8 \%$ [wt/vol] agar, and hygromycin $\mathrm{B}$ at $0.6 \mathrm{mg} / \mathrm{ml}$ ) was spread evenly over the entire surface of the plate, which was then incubated at room temperature over 10 days. Colonies that emerged through the RM top agar represented regenerating colonies and were carefully transferred onto separate PDA media containing hygromycin $(100 \mu \mathrm{g} / \mathrm{ml})$. Each transformant was tip transferred onto fresh PDA-hygromycin media five times.

\section{Determination of $h p h$ integration into $S$. sclerotiorum genome.}

To check for insertion of $h p h$ into the genome of the transformed $S$. sclerotiorum, genomic DNA was extracted from each transformant as well as from wild-type $S$. sclerotiorum and PCR was performed using Ssaxp-specific primers, which were designated Ssaxp forward primer (5'-CACCACGACAA ACATTTCGC-3') and Ssaxp reverse primer (5'-TCGAGTTAC CTTGGCCATTGA-3'). The PCR was performed using a program consisting of $95^{\circ} \mathrm{C}$ for 5 min followed by 30 cycles of $95^{\circ} \mathrm{C}$ for $1 \mathrm{~min}, 54^{\circ} \mathrm{C}$ for $1 \mathrm{~min}$, and $72^{\circ} \mathrm{C}$ for $2 \mathrm{~min}$. PCR was completed with a 10 -min incubation at $72^{\circ} \mathrm{C}$ followed by a hold at $4^{\circ} \mathrm{C}$. If $h p h$ was successfully inserted into Ssaxp in the S. sclerotiorum genome, a PCR product approximately $2.6 \mathrm{~kb}$ in length was expected while the uninterrupted Ssaxp gene was expected to produce a 1.2-kb amplification product. PCR using the extracted genomic DNA was also performed using $h p h$ specific primers, which were designated HPH forward primer (5'-CAAAGCATCAGCTCATCGAGAG-3') and HPH reverse primer (5'-GAAAAGTTCGACAGCGTCTCC-3'). The PCR was performed using the program described above, except the elongation step at $72^{\circ} \mathrm{C}$ was for $1 \mathrm{~min}$. Successful amplification with the HPH primers was expected to generate a PCR product of 502 bp in length. Genomic PCR to amplify an internal control (actin: SS1G_08733.1) was performed using actinspecific primers, which were designated actin forward primer (5'-GTTGGAGATGAAGCGCAATCCAAG-3') and actin reverse primer (5'-CTCAAGACCCAAGACAGATGGTTGG-3'). The PCR was performed using the program described above, except the annealing temperature was $56^{\circ} \mathrm{C}$ and the elongation step at $72^{\circ} \mathrm{C}$ was for $1 \mathrm{~min}$. Successful amplification with the actin primers was expected to generate a PCR product of 651 bp in length. All PCR assays were performed using the Expand High Fidelity PCR system.

RT-PCR was performed to determine what effect the insertion of $h p h$ into the genome of S. sclerotiorum had on expression of Ssaxp. RNA extraction from mycelia grown in PDB was performed using the RNeasy Plant Mini kit (Qiagen), which included DNase treatment to eliminate DNA, and cDNA synthesis was performed using the iScript cDNA synthesis kit (BioRad, Mississauga, Canada) according to the procedures recommended by the manufacturers. RT-PCR to detect the presence of Ssaxp transcript was performed using the Ssaxp forward and reverse primers and PCR program described above. RT-PCR to detect the presence of $h p h$ or actin transcript was performed using the HPH or actin primers and PCR cycles described above.

\section{Pathogenicity assays.}

Doubled haploid wild-type Brassica napus seeds were planted in plastic trays ( 3 by $3 \mathrm{~cm}$, one seed per insert) containing LA4 Aggregate Plus Sunshine Professional Peat-Lite Mix (Sungro Horticulture, Vancouver, Canada). Plants were grown in a growth cabinet $\left(21\right.$ and $18^{\circ} \mathrm{C}$, day and night, respectively, and 18-h photoperiod) for 3 weeks and were fertilized weekly with water-soluble 15-30-15 fertilizer (Plant Products Co., Brampton, Canada). Leaves were excised and placed in 150-by-15-mm petri dishes lined with water-saturated, sterile no. 1 Whatman filter paper, and a water-moistened sterile cotton ball was placed at the base of each petiole. Leaves were inoculated with mycelial plugs $(0.4 \mathrm{~cm}$ in diameter) containing actively growing mycelia of either wild-type (from PDA) or mutant (from PDA-hygromycin) S. sclerotiorum (one plug per leaf). The petri dishes were sealed with plastic laboratory film and were incubated at room temperature. Leaves were photographed every $24 \mathrm{~h}$ (over 3 days) and the images were analyzed using the APS Assess: Image Analysis Software for Plant 
Disease Quantification (APS Press, St. Paul, MN, U.S.A.) to calculate the area of the necrotic lesion on each leaf as indicated by the number of highlighted pixels. The calculated areas were normalized against the calculated area of a square $\left(1 \mathrm{~cm}^{2}\right)$ that was photographed with each leaf in order to eliminate the effect minor variations in the distance between the camera and leaves might have had.

In addition to the detached-leaf inoculations, the virulence of the wild-type and mutant $S$. sclerotiorum was compared using detached canola stem inoculations. B. napus plants were grown in a growth cabinet as described for 8 weeks, after which stem segments (approximately $6 \mathrm{~cm}$ in length) were excised. The stem segments were placed in petri dishes, inoculated (one agar plug containing mycelia of wild-type or mutant S. sclerotiorum per stem), and photographed as described for the inoculated canola leaves. The length of the disease symptoms on each detached stem was measured every $24 \mathrm{~h}$ (over 4 days).

The results of the detached leaf and stem inoculations were analyzed using the GLM procedure for analysis of variance followed by Duncan's multiple-range test $(P<0.05)$ with SAS software (version 9.1; SAS Institute Inc., Cary, NC, U.S.A.). Three independent biological replicates (three leaves or stems per replicate) were performed.

\section{ACKNOWLEDGMENTS}

We thank P. Murray and L. Ostafichuk from the Molecular Biology Service Unit at the University of Alberta for performing the DNA sequencing reactions. Financial assistance from the Natural Sciences and Engineering Research Council of Canada (to W. Yajima) and the Alberta Agriculture Research Institute (to N. N. V. Kav) is gratefully acknowledged.

\section{LITERATURE CITED}

Alghisi, P., and Favaron, F. 1995. Pectin-degrading enzymes and plant parasite interactions. Eur. J. Plant Pathol. 101:365-375.

Boland, G. J., and Hall, R. 1994. Index of plant hosts of Sclerotinia sclerotiorum. Can. J. Plant Pathol. 16:93-108.

Bolton, M. D., Thomma, B. P. H. J., and Nelson, B. D. 2006. Sclerotinia sclerotiorum (Lib.) de Bary: Biology and molecular traits of a cosmopolitan pathogen. Mol. Plant. Pathol. 7:1-16.

Bruce. R. J., and West, C. A. 1982. Elicitation of casbene synthetase activity in castor bean, the role of pectic fragments of the plant cell wall in elicitation by fungal endo-polygalacturonase. Plant Physiol. 69:1181-1188.

Carroll, A. N., Sweigard, J. A., and Valent, B. 1994. Improved vectors for selecting resistance to hygromycin. Fungal Genet. Newsl. 41:22.

Cassab, G. I. 1998. Plant cell wall proteins. Annu. Rev. Plant Physiol. Plant Mol. Biol. 49:281-309.

Cosgrove, D. J. 2005. Growth of the plant cell wall. Nat. Rev. Mol. Cell Biol. 6:850-861.

Fraissinet-Tachet, L., and Fevre, M. 1996. Regulation by galacturonic acid of pectinolytic enzyme production by Sclerotinia sclerotiorum. Curr. Microbiol. 33:49-53.

Godoy, G., Steadman, J. R., Dickman, M. B., and Dam, R. 1990. Use of mutants to demonstrate the role of oxalic acid in pathogenicity of Sclerotinia sclerotiorum on Phaseolus vulgaris. Physiol. Mol. Plant Pathol. 37:179-191.

Hegedus, D. D., and Rimmer, S. R. 2005. Sclerotinia sclerotiorum: When "to be or not to be" a pathogen? FEMS (Fed. Eur. Microbiol. Soc.) Microbiol. Lett. 251:177-184.

Herron, S. R., Benen, J. A. E., Scavetta, R. D., Visser, J., and Jurnak, F. 2000. Structure and function of pectic enzymes: Virulence factors of plant pathogens. Proc. Natl. Acad. Sci. U.S.A. 97:8762-8769.

Jarvis, M. C. 1984. Structure and properties of pectin gels in plant cell walls. Plant Cell Environ. 7:153-164.

Jordan, D. B., and Li, X. L. 2007. Variation in relative substrate specificity of bifunctional $\beta$-D-xylosidase/ $\alpha$-L-arabinofuranosidase by single-site mutations: Roles of substrate distortion and recognition. Biochim. Biophys. Acta 1774:1192-1198.

Kohn, L. M., Stasovski, E., Carbone, I., Royer, J., and Anderson, J. B. 1991. Mycelial incompatibility and molecular markers identify genetic variability in field populations of Sclerotinia sclerotiorum. Phytopathology 81:480-485.

Li, R., Rimmer, R., Buchwaldt, L., Sharpe, A. G., Seguin-Swartz, G., and
Hegedus, D. D. 2004a. Interaction of Sclerotinia sclerotiorum with Brassica napus: Cloning and characterization of endo- and exo-polygalacturonases expressed during saprophytic and parasitic modes. Fungal Genet. Biol. 41:754-765.

Li, R., Rimmer, R., Buchwaldt, L., Sharpe, A. G., Seguin-Swartz, G., Coutu, C., and Hegedus, D. D. 2004b. Interaction of Sclerotinia sclerotiorum with a resistant Brassica napus cultivar: Expressed sequence tag analysis identifies genes associated with fungal pathogenesis. Fungal Genet. Biol. 41:735-753.

Lumsden, R. D. 1969. Sclerotinia sclerotiorum infection of bean and the production of cellulase. Phytopathology 59:653-657.

Lumsden, R. D. 1976. Pectolytic enzymes of Sclerotinia sclerotiorum and their localization on infected bean. Can. J. Bot. 54:2630-2641.

Lumsden, R. D. 1979. Histology and physiology of pathogenesis in plant diseases caused by Sclerotinia species. Phytopathology 69:890-896.

Margolles-Clark, E., Tenkanen, M., Nakari-Setala, T., and Penttila, M. 1996. Cloning of genes encoding $\alpha$-L-arabinofuranosidase and $\beta$-xylosidase from Trichoderma reesei by expression in Saccharomyces cerevisiae. Appl. Environ. Microbiol. 62:3840-3846.

Martel, M. B., Herve du Penhoat, C., Letoublon, R., and Fevre, M. 2002. Purification and characterization of a glucoamylase secreted by the plant pathogen Sclerotinia sclerotiorum. Can. J. Microbiol. 48 212-218.

Miyanaga, A., Koseki, T., Miwa, Y., Mese, Y., Nakamura, S., Kuno, A., Hirabayashi, J., Matsuzawa, H., Wakagi, T., Shoun, H., and Fushinobu, S. 2006. The family 42 carbohydrate-binding module of family $54 \alpha-\mathrm{L}-$ arabinofuranosidase specifically binds the arabinofuranose side chain of hemicelluloses. Biochem. J. 399:503-511.

Peschen, D., Li, H. P., Fischer, R., Kreuzaler, F., and Liao, Y. C. 2004. Fusion proteins comprising a Fusarium-specific antibody linked to antifungal peptides protect plants against a fungal pathogen. Nat. Biotechnol. 22:732-738.

Polizeli, M. L. T. M., Rizzatti, A. C. S., Monti, R., Terenzi, H. F., Jorge, J. A., and Amorim, D. S. 2005. Xylanases from fungi: Properties and industrial applications. Appl. Microbiol. Biotechnol. 67:577-591.

Poussereau, N., Creton. S., Billon-Grand, G., Rascle, C., and Fevre, M. 2001a. Regulation of acp1, encoding a non-aspartyl acid protease expressed during pathogenesis of Sclerotinia sclerotiorum. Microbiology 147:717-726.

Poussereau, N., Gente, S., Rascle, C., Billon-Grand, G., and Fevre, M. 2001b. asps encoding an unusual aspartyl protease from Sclerotinia sclerotiorum is expressed during phytopathogenesis. FEMS (Fed. Eur. Microbiol. Soc.) Microbiol. Lett. 194:27-32.

Riou. C., Freyssinet, G., and Fevre, M. 1991. Production of cell walldegrading enzymes by the phytopathogenic fungus Sclerotinia sclerotiorum. Appl. Environ. Microbiol. 57:1478-1484.

Riou, C., Fraissinet-Tachet, L., Freyssinet, G., and Fevre, M. 1992a. Secretion of pectic isoenzymes by Sclerotinia sclerotiorum. FEMS (Fed. Eur. Microbiol. Soc.) Microbiol. Lett. 91:231-238.

Riou, C., Fraissinet-Tachet, L., Freyssinet, G., and Fevre, M. 1992b. Purification and characterization of extracellular pectinolytic enzymes produced by Sclerotinia sclerotiorum. Appl. Environ. Microbiol. 58:578-583.

Rollins, J. A. 2003. The Sclerotinia sclerotiorum pacl gene is required for sclerotial development and virulence. Mol. Plant-Microbe Interact. 16:785-795.

Sexton, A. C., Cozijnsen, A. J., Keniry, A., Jewell, E., Love, C. G., Batley, J., Edwards, D., and Howlett, B. J. 2006. Comparison of transcription of multiple genes at three developmental stages of the plant pathogen Sclerotinia sclerotiorum. FEMS (Fed. Eur. Microbiol. Soc.) Microbiol. Lett. 258:150-160.

Utt, E. A., Eddy, C. K., Keshav, K. F., and Ingram, L. O. 1991. Sequencing and expression of the Butyrivibrio fibrisolvens xylB gene encoding a novel bifunctional protein with $\beta$-D-xylosidase and $\alpha$-L-arabinofuranosidase activities. Appl. Environ. Microbiol. 57:1227-1234.

Vallette-Collet, O., Cimerman, A., Reignault, P., Levis, C., and Boccara, M. 2003. Disruption of Botrytis cinerea pectin methylesterase gene Bcpme1 reduces virulence on several host plants. Mol. Plant-Microbe Interact. 16:360-367.

Vorwerk, S., Somerville, S., and Somerville, C. 2004. The role of plant cell wall polysaccharide composition in disease resistance. Trends Plant Sci. 9:203-209.

Waksman, G., Keon, J. P., and Turner, G. 1991. Purification and characterization of two endopolygalacturonases from Sclerotinia sclerotiorum. Biochim. Biophys. Acta 1073:43-48.

Weinstein, L., and Albersheim, P. 1979. Structure of plant cell walls. Plant Physiol. 63:425-432.

Yajima, W., and Kav, N. N. 2006. The proteome of the phytopathogenic fungus Sclerotinia sclerotiorum. Proteomics 6:5995-6007.

Yelton, M. A., Hamer, J. E., and Timberlake, W. E. 1984. Transformation of Aspergillus nidulans by using a trpC plasmid. Proc. Natl. Acad. Sci U.S.A. 81:1470-1474. 